\title{
Mechanical Design of a cleaning machine for vicuña fiber of $5 \mathrm{~kg} / \mathrm{h}$
}

DOI: $10.46932 / \mathrm{sfjdv3n1-081}$

Received in: Jan 30st, 2021

Accepted in: Feb 1th, 2022

\author{
Alan Ccarita \\ Pontificia Universidad Católica del Perú, Group DIME, Department of Mechanical Engineering, Perú. \\ E-mail: alan.ccarita@ pucp.edu.pe
}

\section{Dustin Rojas}

Pontificia Universidad Católica del Perú, Group DIME, Department of Mechanical Engineering, Perú. E-mail: d.rojas@pucp.pe

\section{Benjamin Barriga}

Pontificia Universidad Católica del Perú, Group DIME, Department of Mechanical Engineering, Perú. E-mail: bbarrig@ pucp.edu.pe

\section{Jorge Alencastre}

Pontificia Universidad Católica del Perú, Group DIME, Department of Mechanical Engineering, Perú. E-mail: jalenca@pucp.edu.pe

\section{J. Alan Calderón Ch}

Pontificia Universidad Católica del Perú, Group DIME, Department of Mechanical Engineering, Perú. TU Ilmenau University of Technology, Applied Nanophysics, Institute for Physics, Germany.

E-mail: alan.calderon@pucp.edu.pe

\section{Julio C. Tafur}

Pontificia Universidad Católica del Perú, Group DIME, Department of Mechanical Engineering, Perú. E-mail: jtafur@pucp.edu.pe.

\author{
A.M Gómez Amador \\ University of Carlos III de Madrid, España. \\ E-mail: amgomez@ing.uc3m.es
}

\begin{abstract}
The vicuña is considered a national heritage of Peru and has the finest animal fiber in the world $(12 \mu \mathrm{m}$ of diameter). According to FAO (Food and Agriculture Organization), Peru is the first producer of vicuña fiber in the world $(68.1 \%)$ followed by Bolivia, Argentina, Chile and Ecuador (Mincetur,2010). The washing process consists of immersing the fiber into an aqueous medium formed by hot water $\left(40-60^{\circ} \mathrm{C}\right)$ and detergents that, through gentle mechanical movements, eliminates the fiber impurities (grease, suintin, dust, dirt, etc.). In Peru thousands of peasant communities in charge of the exploitation of this product, commercialize the untreated fiber, without removing impurities In this work, a small washing equipment has been designed, according to the production capacity of Peruvian peasants who take care of vicuñas. This washing equipment allows the cleaning of the fiber through the feeding, dragging, dipping and squeezing processes, fulfilling the washing standards IWTO-19-981. The use of this equipment will allow obtaining a cleaner fiber without any type of felting, a-saving $20 \%$ of water and a yield of $90 \%$ compared to traditional manual washing.
\end{abstract}


Keywords: Washing, vicuña fiber, mechanical design, IWTO.

\section{INTRODUCTION}

This work responds to the technological necessity that producers of vicuña fiber from Peru have. The vicuña (Figure 1) is an emblematic species, wild relative of the llama, valued for its fine silky wool. It is a South American camelid that lives at high altitudes (greater than 3,200 $\mathrm{m}$ above sea level) and along the more than 3,000 km of the Andes territory, in Argentina, Bolivia, Chile, Ecuador and Peru-and can weight between 38 and $50 \mathrm{~kg}$. Since the mid-1990s, the female peasant communities in Peru participate directly in the conservation, management and commercialization of the vicuna. The vicuña is captured and sheared in an ancient ceremony (Inca ritual) known as Chaccu.

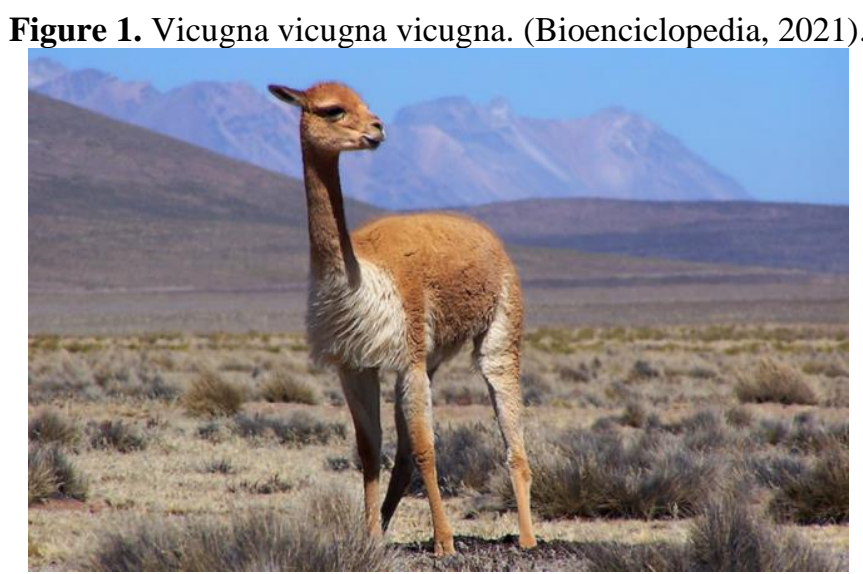

The vicuña fiber is an important resource for the socioeconomic development of the high Andean population. Peru produces approximately 8 tons of vicuña fiber per year from about 200,000 specimens [3]. According to FAO, Peru is the first producer of vicuña fiber in the world (68.1\%) followed by Bolivia, Argentina, Chile and Ecuador (Mincetur, 2010).

The vicuña fiber has a high fineness (10-15 $\mu \mathrm{m})$ and is expensive (300-400 \$ / $\mathrm{kg}$ of dirty fiber) (ACRIVIRC, 2020). Vicuña's fleece weights around $200 \mathrm{gr}$ and is composed of $90 \%$ fine fibers that can measure between 32 to $38 \mathrm{~mm}$ and a $10 \%$ of unwanted fibers, which are longer and have different densities (bristles) (ACRIVIRC, 2020). Vicuña fiber is exported without previous treatments that improve its quality, like washing. Therefore, in addition to the fact that the participation of the local community is short, sale prices are not fair enough for Peruvian peasants.

This work presents a design of a washing machine that allows Peruvian peasants to obtain a better quality vicuña fiber, without contaminants, that will contribute to the technological and economic development of local communities. For its exportation, the final product must fulfill the IWTO-19-98[1] 
washing standard. In order to fulfill this purpose, the German Design Methodology VDI 2221 [2] was applied.

\section{DESIGN}

The design requirements demand the washing machine to have easy operation, construction, maintenance and portability, and also an ergonomic design to be used by Peruvian vicuña fiber producers. In addition, the design must ensure the machinery is safe to use, provide environmental security does not cause damage or deterioration to the fiber. The conception of the design is carried out according to recommendations of the German standard VDI2221 [2].

As shown in Figure 2, the process began with the identification of the basic input/output magnitudes. Subsequently, the structure of functions of the machine, shown in Figure 3, was identified based on Barriga's work [4]. The following three design solutions were developed with a discursive form, with the help of an orderly scheme called "Morphological Matrix", presented in Figure 4:

Figure 2. Black box.

\begin{tabular}{|c|c|c|}
\hline \multicolumn{3}{|c|}{ BLACK BOX } \\
\hline Signal & \multirow{6}{*}{ BLACK BOX } & Signal \\
\hline $\begin{array}{l}\text { - The operator observes the } \\
\text { entry of vicuña fiber for } \\
\text { washing. }\end{array}$ & & $\begin{array}{l}\text { Visual at the end of the } \\
\text { process }\end{array}$ \\
\hline Energy & & Energy \\
\hline $\begin{array}{l}\text { - Human: to feed vicuña } \\
\text { fiber to the feeding system } \\
\text { - Electric: to activate the } \\
\text { electric motor and the } \\
\text { controller that will activate } \\
\text { the mechanical washing } \\
\text { system. } \\
\text { - Thermal: for water heating }\end{array}$ & & $\begin{array}{l}\text { - Human: to remove the } \\
\text { washed fiber }\end{array}$ \\
\hline Material & & Material \\
\hline $\begin{array}{l}\text { - Dirty vicuna fiber without } \\
\text { dehairing with impurities } \\
\text { of fat, suitine, minerals, } \\
\text { and vegetable remains. } \\
\text { - Hot water at } 40^{\circ} \mathrm{C}-60^{\circ} \mathrm{C} \\
\text { and } 7-9 \text { ph. } \\
\text { - Biodegradable detergents }\end{array}$ & & $\begin{array}{l}\text { - Clean vicuña fiber with } \\
\text { bristle without impurities } \\
\text { with } 12 \% \text { moisture content } \\
\text { - Lanolin, grease, soil and } \\
\text { suintine } \\
\text { - Dirty water }\end{array}$ \\
\hline
\end{tabular}


Figure 3. Function Structure.

\begin{tabular}{|c|c|c|l|l|}
\hline \multicolumn{2}{|c|}{ Function structure } & Pág 01 de 01 \\
\hline Endition: FACC \\
\hline Customer: & Mechanical Design of a cleaning machine for vicuña fiber of $5 \mathrm{~kg} / \mathrm{h}$ & Date: $20 / 09 / 2021$ \\
\hline Reviewed: Ing. Benjamin Barriga \\
\hline Señal
\end{tabular}

Figure 4. Morphology matrix.

\begin{tabular}{ccl}
\hline & MORPHOLOGY MATRIX & Páge 01 de 01 \\
\hline \multirow{2}{*}{ PROYECT: } & $\begin{array}{c}\text { Mechanical Design of a cleaning machine for vicuña } \\
\text { fiber of } 5 \mathrm{~kg} / \mathrm{h}\end{array}$ & $\begin{array}{l}\text { Edition: FACC } \\
\text { Date: } 20 / 09 / 2021\end{array}$ \\
\cline { 3 - 3 } & $\begin{array}{l}\text { Reviewed: } \\
\text { Ing. Benjamin } \\
\text { Barriga }\end{array}$ \\
\hline CUSTOMER: & ACRIVIRC (Association of peasant communities of \\
vicuña from Cusco) & $\begin{array}{l}\text { Elaborated: } \\
\text { F. Alan Ccarita C. }\end{array}$ \\
\hline FUNCTIONS & ALTERNATIVE 1 ALTERNATIVE 2 ALTERNATIVE 3 & ALTERNATIVE 4 \\
\hline
\end{tabular}

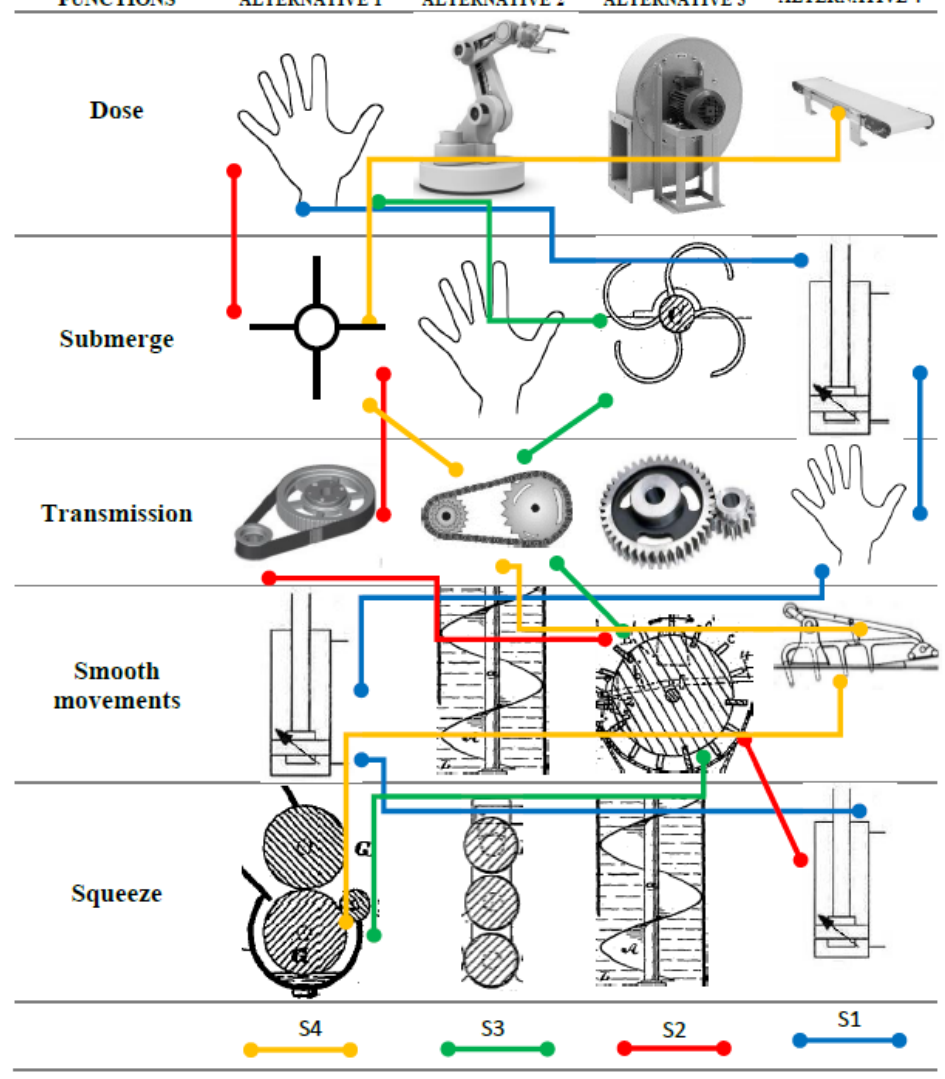


Analyzing this matrix, three solutions are proposed

- Proposal A: Based on the use of hydraulic cylinders: This proposal. Contemplated a manual feeding, washing and squeezing. The washing and squeezing processes would be carried out through two hydraulic cylinders that place the washing tray and squeeze the fiber in and out of the aqueous medium consisting of water and detergent All hydraulic system would require the implementation of a pressure unit, which would generate a high manufacturing cost.

- Proposal B: Suggests a manual feeding system with a submerged washing and dragging system through a chain. For generating squeezing, the use of two rollers that exert pressure through the spring is proposed, which is an inexpensive alternative.

- Proposal C: Proposes the manufacturing of a washing machine with a conveyor belt feeding system, followed by a mass weighing system that is eventually submerged by a roller with paddles. The fiber dragging system would be is carried out using a rake that transports, submerges and washes the fiber gently without damaging it. The squeezing system would uses two rollers driven by two springs that generate ensures the necessary pressure. This system would also guarantee low costs.

After a technical-economic evaluation (Figure 5), the optimal design solution selected to generate the end product was Proposal C, idea that is based on the use of a rake, and sketched in Figure 6.

Figure 5. Technical and economic evaluation diagram.

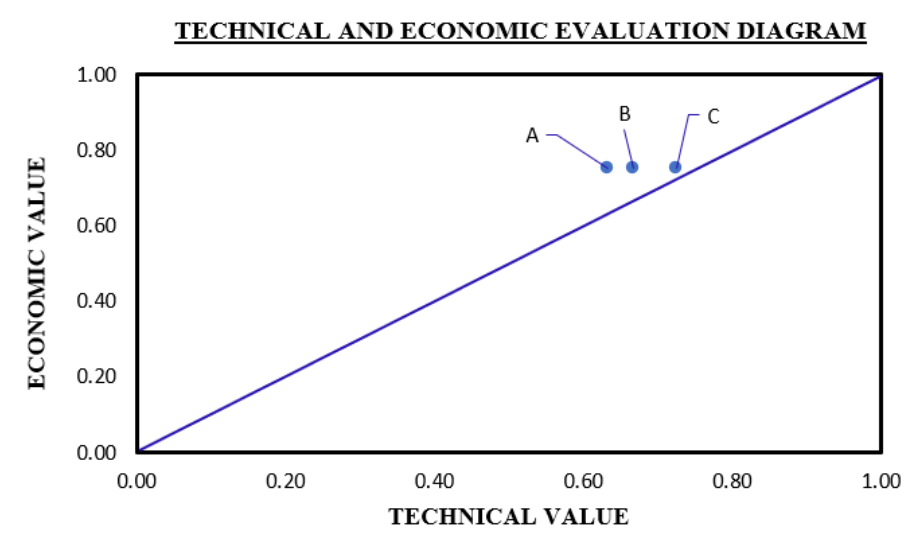


Figure 6. Scheme of the selected optimal design solution.

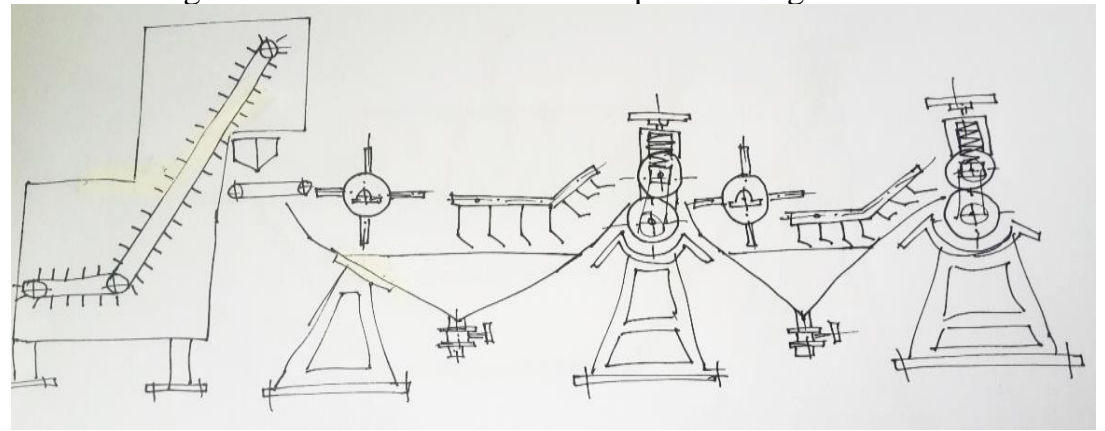

\section{WASHING PARAMETERS}

Washing should be performed in an aqueous medium of $40-60^{\circ} \mathrm{C}$ water and detergent. Immersion time, water hardness, squeezing pressure, detergent concentration, temperature, volumetric flow, squeeze roll efficiency, and purge time are essential parameters to ensure fiber washing quality. To determine these parameters, different tests were performed in a certified laboratory and with the necessary equipment.

\section{DESIGN AND CALCULATION OF MACHINE ELEMENTS}

The complete washing system (Figure 7) is made up of four equal modules (Figure 8) joined continuously, which are in charge of carrying out the following processes: soaking, first wash, second wash and final rinse. As appreciated in Figure 8, the individual module has three parts: a submerged drum, a drag system, and a squeezing system containing two spring compressed rollers.

Figure 7. Complete washing system

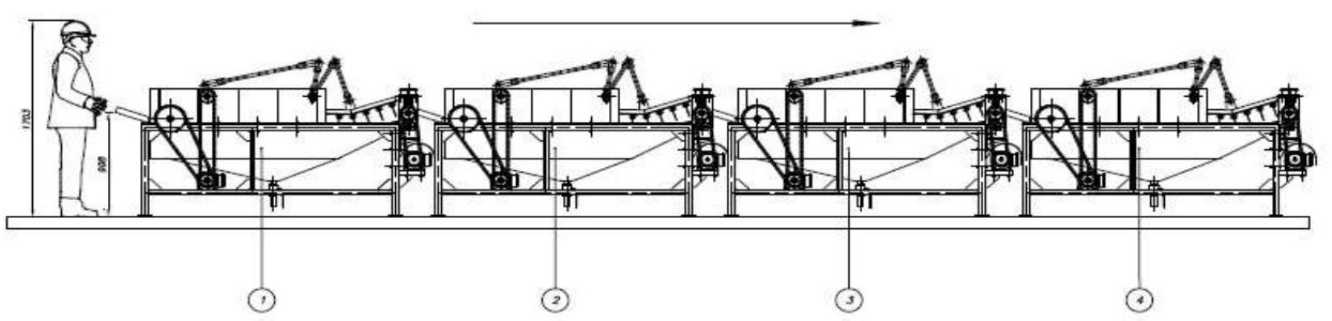

Figure 8. The individual module of the washing system (Figure 7).

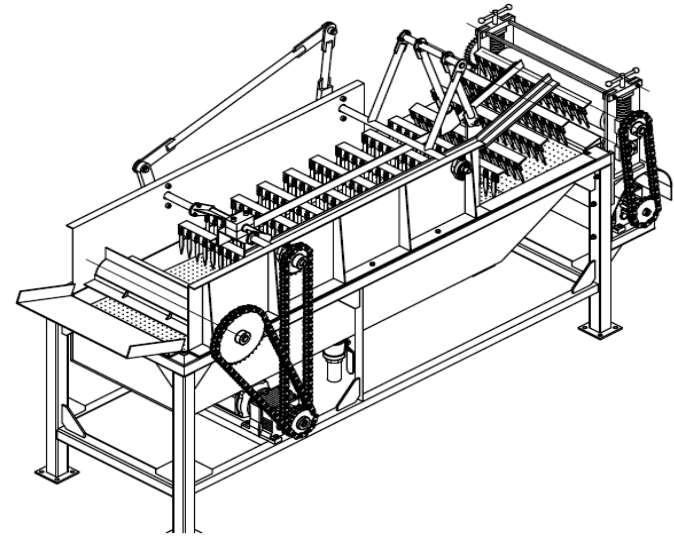


The entrainment phase is the most important stage during washing. This process ensures of impurities from the vicuña fiber, by first producing an oscillatory movement the-dirty fiber with hot water and chemical detergents. The optimal drive mechanism must remove impurities without damaging or felting the fiber. The selected rake is actuated by a four-bar mechanism hinged to a free mechanism. The complete drag mechanism assembly is shown in Figure 9, whereas the kinematic design of the drag mechanism in Figure 10. One part of the four-bar mechanism is formed by the points $\mathrm{O}_{2} \mathrm{ABO}_{4}$ and the other by the free mechanism determined by the points $\mathrm{O}_{2} \mathrm{O}_{4} \mathrm{CDE}$ from figure 10 . The first one works as a power receiver of the geared motor that transforms it into rotation, to transmit it to the second block that generates the oscillatory motion and supports the rake.

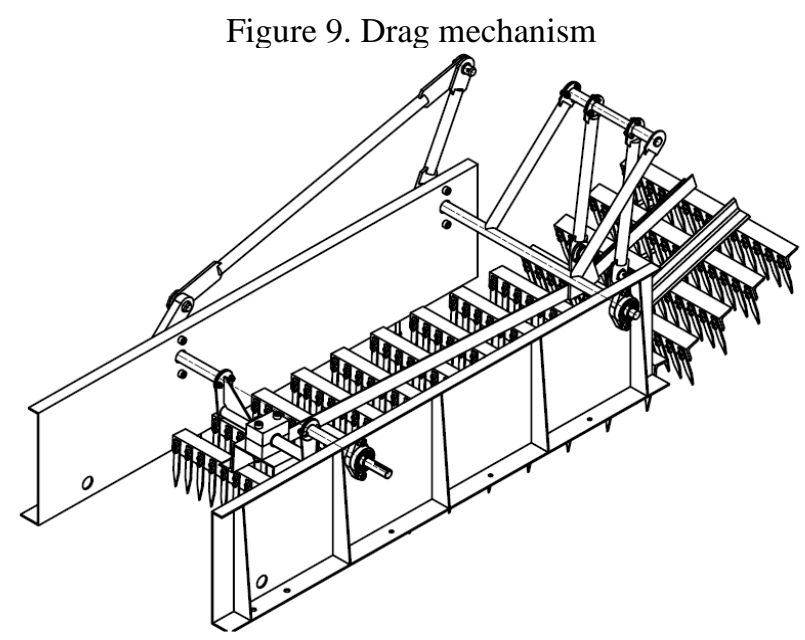

Figure 10. Conceptual model of drag mechanism.

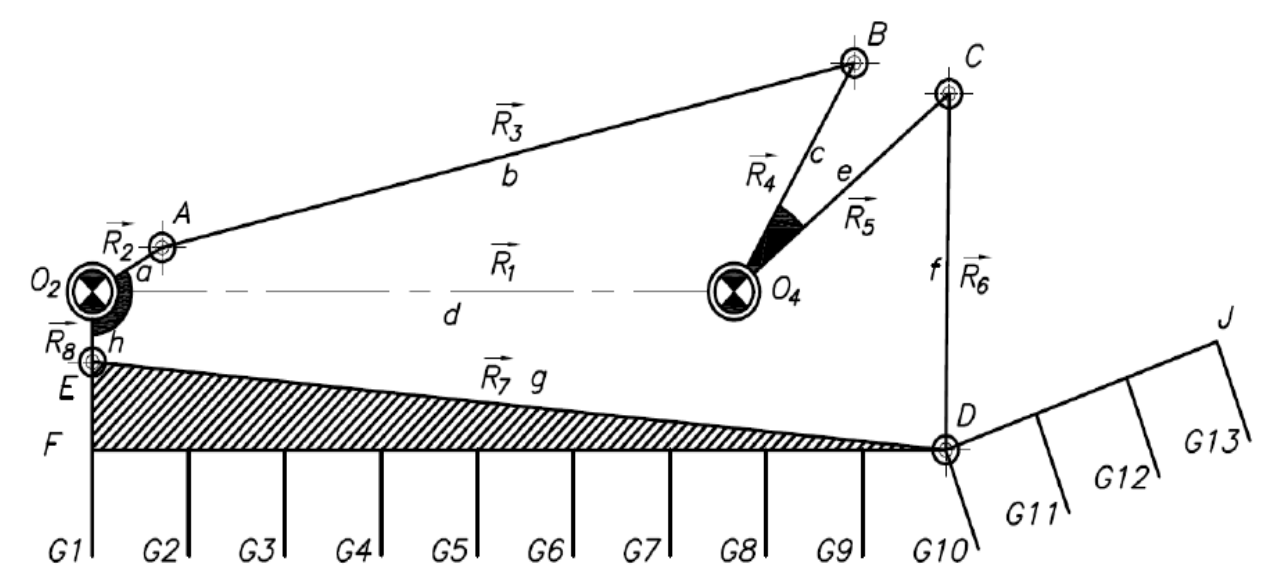

The Grübler (Equation 1) is used to determine the number of degrees of freedom of the mechanism, the degree of mobility of the mechanism; where $\mathrm{N}$ is the number of links, J1 is the number of lower kinematic pairs (each constrains two degrees of freedom in the plane), and J2 is the number of upper kinematic pairs (each restricts one degree of freedom in the plane). 


$$
G D L=3(N-1)+2 J_{1}-J_{2}
$$

According to Figure 10, the following parameters were defined; $\mathrm{N}=6, \mathrm{~J} 1=7$ and $\mathrm{J} 2=0$. Therefore, by applying the Grübler equation, the following result was obtained:

$$
\begin{gathered}
G D L=3(6-1)+2(7)-0 \\
G D L=1
\end{gathered}
$$

The mechanism presented a degree of freedom, which made its development possible. Figure 10 shows the simulation of the trajectory of the mechanism and of the rake drag points. By analyzing the displacements and velocities of the drag tips, a total rake drag force of $87 \mathrm{~N}$ was obtained, which is enough to guarantee the design mass flow rate of the washer of $5 \mathrm{~kg} / \mathrm{h}$, a value that guarantee a correct mass flow rate for a washing machine of $5 \mathrm{~kg} / \mathrm{h}$.

Figure 11. Mechanism trajectory simulation

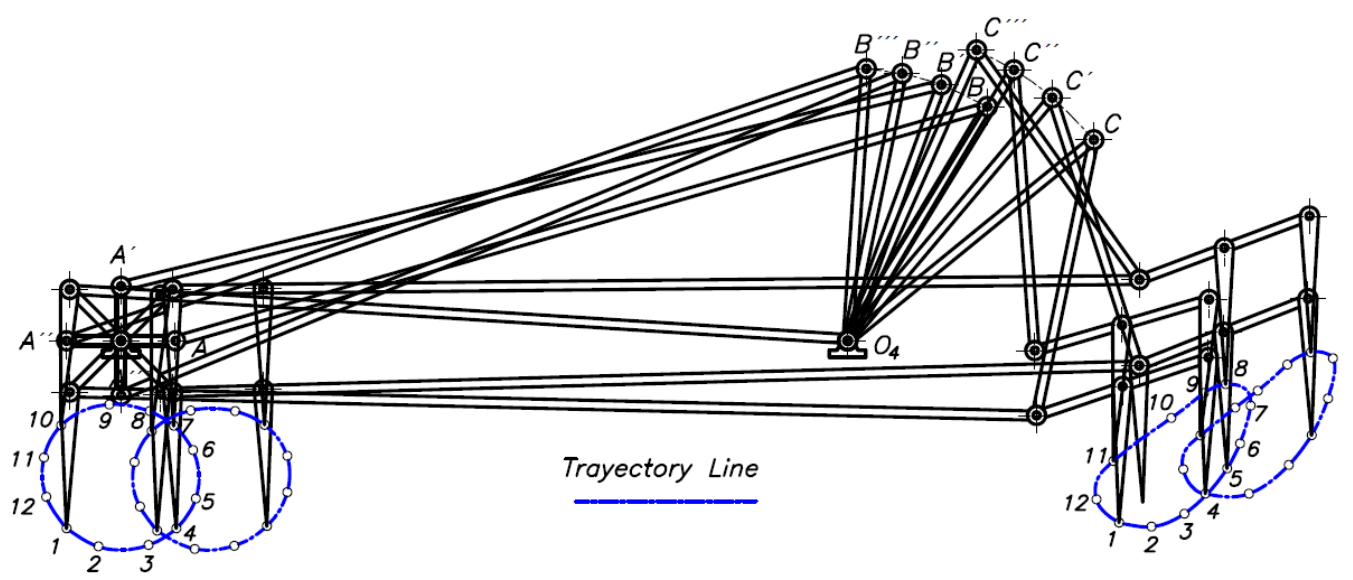

The drag force, calculated by Equation 2, represents the opposition of a body to move through a fluid. The magnitude of this force depends on the velocity of the drag tips $\left(\mathrm{V}_{0}\right)$, submerged area of contact (profile width, a, per submerged length, $\left.1_{\mathrm{s}}\right)$, fluid density $\left(\rho_{w}\right)$ and a drag coefficient $\left(\mathrm{C}_{\mathrm{D}}\right)$ upon contact with the aqueous medium.

$$
F_{A}=\frac{C_{D} \cdot \rho_{w} \cdot V_{o}^{2} \cdot a \cdot l_{s}}{2}
$$

The oscillatory motion of the drive tips followed the geometry scheme (Figure 12). Movement generated a maximum horizontal displacement of $177 \mathrm{~mm}$ per cycle and the tips were submerged to a 
Figure 12. Trajectory detail and drag depth

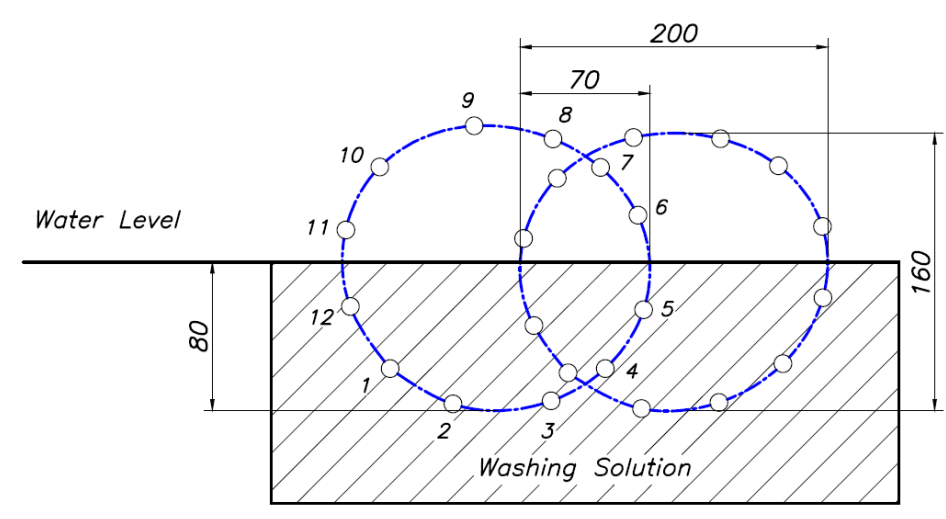

Figure 13. Tip pull force

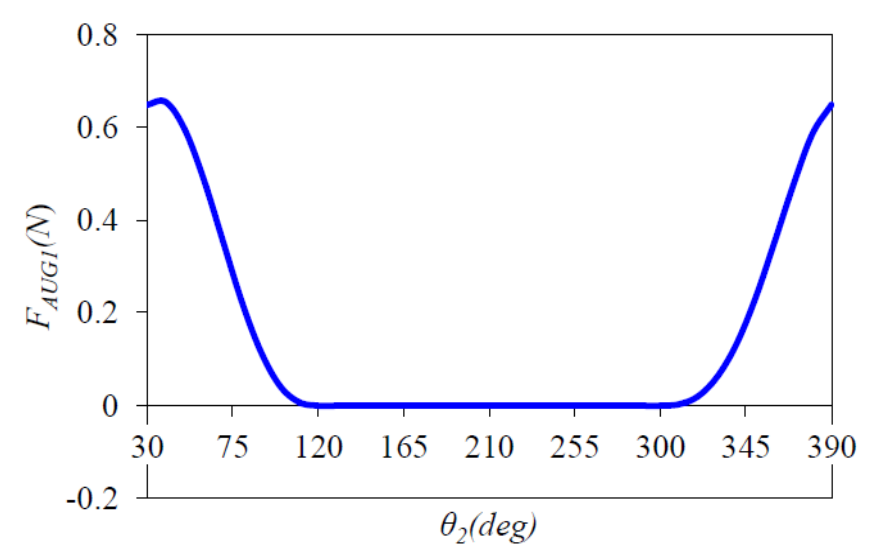

\section{CONCLUSIONS}

The application of the VDI 2221 design methodology was possible to obtain an optimal solution based on the established requirements and a list of imposed demands. Three design solutions for the development of the washing equipment were proposed and evaluated by considering technical and economic aspects. The proposal that includes the use of a rake was selected for having the most efficient method for washing vicuña fiber. The washing performance for of the vicuña fiber sample exceeded expectations with a performance of over $92 \%$.

The dragging mechanism was modeled and analyzed in detail to ensure that the washing machine maintains an adequate efficiency and does not damage the quality of the fiber. The manufacturing plans and components of the machine were drawn up, fulfilling the necessary technical requirements. This new machine can easily be manufactured in local workshops in the vicuña fiber-producing areas of the high 
Andean areas, increasing Peruvian peasants participation and providing added value to the final product. Machine design is currently being improved with the implementation of an ultrasound system.

\section{ACKNOWLEDGEMENTS}

The main author of this article F. Alan Ccarita Cruz, expresses:

The thankful to the financial support of the Concytec - World Bank Project "Improvement and Expansion of the Services of the National System of Science and Technology and Technological Innovation" 8682PE, through its executing unit ProCiencia $\square$ Contract Number 061-2018-FONDECYT-BM -IADT-MU $\square$ 


\section{REFERENCES}

[1] Test Method Nr. IWTO-19-98 (International Wool Textiles Organization Textiles Organization): Determination of wool base and vegetable matter base of core samples of raw wool, Woolmark Co., Ilkley, U.K.

[2] VDI 2221 (Verein Deutscher Ingenieure) called "Systematic approach to the design of technical systems and products". Systems and product design", a standard developed by the professional developed by professional engineers, is a variation of VDI 2222. 2222.

[3] SERFOR: National Forestry and Wildlife Service (Peru, 2016). Silvestre (Peru, 2016)

[4] Barriga Gamarra, Benjamín (1995). Methods of design and mechanical engineering. Peru PUCP.

[5] G. Adot, Oscar (2010). Introducción a la industrialización de la lana y fibras especiales. Argentina. Universidad Católica de Córdoba.

[6] Larburu Arrizabalaga, Nicolas (1999). Maquina Prontuario. España. Paraninfo

[7] ASM International, (2003), Handbook of Workability and Process Design.

[8] Alvarez, Miguel (2011), Apuntes de Clase “Temas Selectos del Diseño Mecánico”. PUCP.

[9] Budynas-Nisbett (2006), Mechanical Engineering, 8va Ed, p. 717

[10] Herbert Wittel, Dieter Muhs, Dieter Jannasch, Joachim Voßiek. (2011)

[11] Shigley J. and Mitchell L (1985). Diseño en Ingeniería Mecánica. México. Mc Graw-Hill.

[12] Arthur G. Erdman, George N. Sandor (1998). Diseño de Mecanismos Análisis y Síntesis. Mexico. Prentice Hall.

[13] James Newell (2011). Ciencia de Materiales. Mexico. Alfaomega.

[14] Martin Domingo, Agustin (2011). Apuntes de Mecánica de Fluidos. España. Universidad Politecnia de Madrid.

[15] Robert L. Mott (2006). Mecánica de Fluidos. Mexico. Prentice Hall. 